\title{
To the Memory of Hendricus Jacobus Marie Weve
}

In the evening of January 3rd Prof. Weve died at Utrecht, 73 years old. Although he had been suffering from a chronic disease for some months, the end came more suddenly than was expected, especially by those who had seen him working as hard as ever in his private praxis until a few weeks before his death.

Ophthalmologica, Vol. 143, No. 1 (,lamiar 1962)

With the death of Weve ophthalmology loses one of its outstanding practitioners; Holland loses a national celebrity; a great number of people all over the world lose a dear friend.

The publisher of Ophthalmologica, a journal to which Weve was very much attached and on the staff of which he has served for many years as chief-editor and more recently as honorary editor, has asked me to contribute a short "in memoriam" to my beloved teacher, friend and predecessor in the chair of ophthalmology at Utrecht University.

It seems superfluous to present detailed biographical and bibliographical data to the readers of this journal. In 1958 at the occasion of Weve's 70th birthday, Sir Stewart Duke Elder wrote an excellent paper on his life and his work as an introduction to a special volume (Ophthalmologica $135,233-236,1958)$. In the same volume the reader will find a nearly complete bibliography. This bibliography shows that Weve's activities cover a large field of ophthalmological subjects. However, he won his worldwide fame by his pioneer work in the field of the surgical treatment of retinal detachment. He was appointed to the chair of ophthalmology at Utrecht University in 1929, the year in which Gonin presented his first results to the visitors of the XIII. International Congress. Weve was one of the first clinicians, who fully understood the importance of Gonin's discovery. He improved the technique by introducing diathermy and a simple method of localisation by means of transillumination. His excellent results were soon recognised by doctors and patients all over the world and the Utrecht Eye Hospital became a Mecca for the international ophthalmological world. Certainly his work on detachment will give him an important place in the history of ophthalmology. However, it seems possible that this historical place will be secured still more by his work on the conservative treatment of intraocular tumours by means of diathermy, which started in the early thirties and which gave the impulse from which all later work on the conservative treatment of intraocular tumours arose (radio-therapy, cytostatics, light-coagulation). This important field is still in full

development. In later years Weve drew again general attention by his "reefing"-operation, one of the first buckling procedures in the treatment of retinal detachment.

Although Weve's scientifical activities are by no means negligible he was in his heart a clinician. Curing patients was always his primary aim. In his therapeutical activities he was inclined to think more in a surgical than in a medical direction. He was an active eye-surgeon until a few weeks before his death.

During his life he received an impressing amount of scientific, public and religious honours. He was honorary member of a great number of ophthalmological societies, member of the Royal Academies of Holland and Belgium, etc. etc. 
However, we, his friends and admirers, looking through this dense wood of honours, see in our mind the man Weve, the charming friend, the excellent host, the gifted speaker, the man with great artistic talents and profound historical interests, the beloved teacher, the loving husband and father, the man who appreciated worldly pleasures in the form of a good dinner or a hunting party.

H. However

his more intimate friends know $\tau$ that the central motive which actuated the deeper parts of this human mind was an intensely profound and honest religious belief which gave him solace and heroic strength until the last moments of his life. He leaves in this world innumerable friends who will never forget him. Requiescat in pace.

J. ten Doesschate.

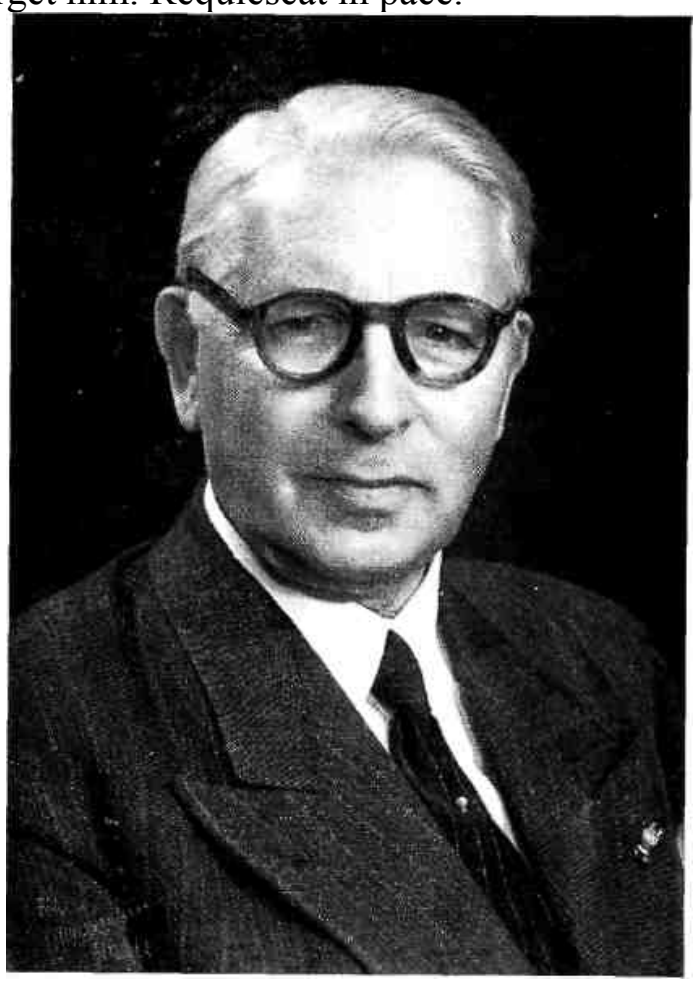

